\title{
Bilateral radial agenesis with absent thumbs, complex heart defect, short stature, and facial dysmorphism in a patient with pure distal microduplication of $5 q 35.2-5 q 35.3$
}

\author{
Aleksander Jamsheer ${ }^{1,2^{*}}$, Anna Sowińska ${ }^{1,2}$, Dorota Simon², Małgorzata Jamsheer-Bratkowska ${ }^{3}$,
} Tomasz Trzeciak ${ }^{4}$ and Anna Latos-Bieleńska ${ }^{1,2}$

\begin{abstract}
Background: A partial duplication of the distal long arm of chromosome 5 (5q35-> qter) is known to be associated with a distinct phenotype referred to as Hunter-McAlpine syndrome. Clinical spectrum of this disorder mainly consists of mental retardation, microcephaly, short stature, skeletal anomalies, and craniofacial dysmorphism featuring flat facies, micrognathia, large, low-set dysplastic ears, hypertelorism, almond-shaped, down-slanted palpebral fissures, epicanthal folds, small nose, long philtrum, small mouth, and thin upper lip. Less frequent remarkable findings include craniosynostosis, heart defect, hypoplastic phalanges, preaxial polydactyly, hypospadias, cryptorchidism, and inguinal hernia. In most patients with a partial duplication of $5 q$ the aberration occurred due to an inherited unbalanced translocation, therefore the phenotype was not reflective of pure trisomy $5 \mathrm{q}$.

Case presentation: We report on a 9.5-year-old boy with some feature of Hunter-McAlpine syndrome including short stature, complex heart defect (dextrocardia, dextroversion, PFO), bilateral cryptorchidism, hypothyroidism, and craniofacial dysmorphism. Additionally, bilateral radial agenesis with complete absence of Ist digital rays, ulnar hypoplasia with bowing, choroidal and retinal coloboma, abnormal biliary vesicle were identified, which have never been noted in $5 q$ trisomy patients. Karyotype analysis, sequencing and MLPA for TBX5 and SALL4 genes were unremarkable. Array comparative genomic hybridization detected a duplication on 5q35.2-5q35.3, resulting from a de novo chromosomal rearrangement. Our proband carried the smallest of all previously reported pure distal $5 q$ trisomies encompassing terminal 5.4-5.6 $\mathrm{Mb}$ and presented with the most severe limb malformation attributed to the increased number of distal $5 q$ copies.

Conclusions: We postulate that a terminal distal trisomy of 5q35.2-5q35.3, which maps $1.1 \mathrm{Mb}$ telomeric to the MSX2 gene is causative for both radial agenesis and complex heart defect in our proband. A potential candidate gene causative for limb malformation in our proband could be FGFR4, which maps relatively in the closest position to the chromosomal breakage site (about $1.3 \mathrm{Mb}$ ) from all known $5 \mathrm{q}$ duplications. Since the limb malformation as well as the underlying genetic defect are distinct from other $5 q$ trisomy patient we propose that a position effect resulting in altered long-range regulation of the FGFR4 (alternatively MSX2) may be responsible for the limb malformation in our proband.
\end{abstract}

Keywords: Pure distal trisomy 5q, Distal 5q duplication, Dup (5)(q35.2q35.3), Hunter-McAlpine syndrome, MSX2, FGFR4, Radial agenesis, Absent thumbs

\footnotetext{
* Correspondence: jamsheer@wp.pl

1 Department of Medical Genetics, University of Medical Sciences in Poznan,

55 Grunwaldzka Street, pav. 15, Poznan 60-352, Poland

${ }^{2}$ NZOZ Center for Medical Genetics GENESIS, Poznan, 4 Grudzieniec Street,

Poznan 60-601, Poland

Full list of author information is available at the end of the article
} 


\section{Background}

A partial duplication of the distal long arm of chromosome 5 (5q35-> qter) is known to be associated with a distinct phenotype referred to as Hunter-McAlpine syndrome [1]. Clinical spectrum of this disorder consists mainly of mental retardation, microcephaly, short stature, skeletal anomalies, and craniofacial dysmorphism featuring flat facies, micrognathia, large, low-set dysplastic ears, hypertelorism, almond-shaped, down-slanted palpebral fissures, epicanthal folds, small nose, long philtrum, small mouth, and thin upper lip. Less frequent remarkable findings include craniosynostosis, heart defect (VSD, ASD, bicuspid aortic valve), hypoplastic phalanges, preaxial polydactyly, hypospadias, cryptorchidism, and inguinal hernia [2-7]. In most patients with a partial duplication of $5 \mathrm{q}$ the aberration occurred due to an inherited unbalanced translocation, hence the phenotype was not reflective of pure trisomy $5 \mathrm{q}$. To our knowledge, the smallest pure partial distal duplication of chromosome $5 \mathrm{q}$ described to date encompassed about $6.4 \mathrm{Mb}$ of $5 \mathrm{q}$ terminus $(5 \mathrm{q} 35.2-5 \mathrm{q} 35.3)$ and was detected in a patient presenting with microcephaly, strabismus, facial dysmorphism, moderate mental retardation, short stature, brachydactyly, and inguinal hernias [8]. Additionally, one more case with a pure gain on distal 5q (an interstitial triplication of 5q35.2-5q35.3) involving $6.56 \mathrm{Mb}$ was identified in a patient manifesting some common features of Hunter-McAlpine syndrome (intrauterine growth retardation, almond-shaped eyes with epicanthal folds, downturned mouth with thin vermillion of the upper lip), as well as other unique findings such as left ventricular noncompaction (LVNC) and absent thumbs [9].
In our report, we describe a male proband with a pure 5.4-5.6 Mb distal duplication of 5q35.2-> qter detected by array comparative genomic hybridization (array CGH), resulting from a de novo chromosomal rearrangement. To our knowledge, this is the smallest region of pure distal $5 \mathrm{q}$ trisomy. In addition to some features of Hunter-McAlpine syndrome, our patient presented with bilateral radial aplasia with absent thumbs, which seems to be the most severe limb malformation attributed to the increased number of distal 5q copies.

\section{Clinical report}

The proband, a 9.5-year-old boy of Polish descent, was born by spontaneous delivery after uneventful pregnancy (G1P1) at 38 weeks of gestation to a non-consanguineous and healthy 24-year-old mother and a 30-year-old father. At birth, his weight was $2500 \mathrm{~g}$ (3rd percentile), length $51 \mathrm{~cm}$ (75th-90th percentile), head circumference $32 \mathrm{~cm}$ (3rd percentile), and Apgar score was 9-10-10 at 1, 3, and 5 minutes, respectively. Physical examination after birth showed bilateral upper limb malformation comprised of radial agenesis with complete absence of Ist digital ray (i.e. absent thumbs as well as Ist metacarpals), and ulnar hypoplasia with bowing. Both forearms were significantly shortened due to the long bone aplasia/hypoplasia (Figure 1a, 1b and 1c). In addition, facial dysmorphism and bilateral cryptorchidism were noted. Echocardiography (ECHO) exam revealed dextrocardia, dextroversion, and persistent foramen ovale apertum (PFO). On abdominal ultrasound at 5 days of age an abnormally long inverted U-shaped biliary vesicle was noted. Hearing tests performed
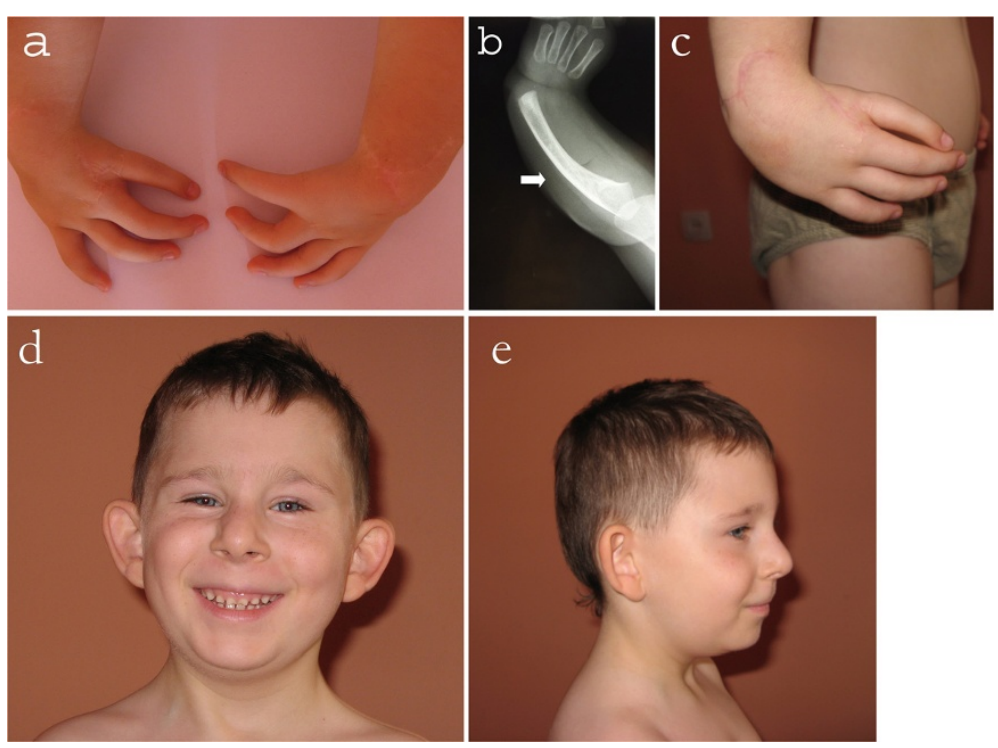

Figure 1 The proband at the age of $\mathbf{8}$ years and $\mathbf{4}$ months: a) Bilateral upper limb defect comprised of absent thumbs and radial bone agenesis resulting in significant forearm shortening $\mathbf{b})$ X-ray scan of the proband's left forearm showing absent radius along with Ist digital ray $\mathbf{c}$ ) right forearm of the proband with prominent contraction of the zeugopod $\mathbf{d}$ ) Facial dysmorphic features seen in the proband $\mathbf{e}$ ) Lateral view of the proband's face. 
during first week after birth showed left hypoacusis. At the age of 4 months a detailed ophthalmologic examination revealed a congenital choroidoretinal coloboma in the down quarter of the right eye. The boy was referred to our genetic clinic for diagnosis and first investigated at the age of 7 years. Upon examination, he presented with short stature, neck webbing, and craniofacial dysmorphic features comprising full cheeks, prominent widened nasal bridge, almond-shaped eyes, thin vermillion of upper lip, abnormally shaped teeth, and low-set dysplastic ears (Figure 1d and 1e). His height reached $113 \mathrm{~cm}$ (below 3rd percentile), whereas body weight was $20 \mathrm{~kg}$ (10th percentile). According to anamnesis, developmental milestones were achieved on time, with independent sitting at 6 , walking at 12, and expressive speech (first several words) at 12 months. Retrospective analysis of medical record revealed that short stature had become evident before 2 years of age: $7.8 \mathrm{~kg}$ (below 3rd percentile) and $80 \mathrm{~cm}$ (below 3rd percentile) at age 2 years. Due to facial dysmorphism and microsomia recognized at that time, the proband was referred for a conventional chromosomal analysis (performed on peripheral blood lymphocytes with a resolution of 550 bands per haploid genome) which showed normal male karyotype $(46, \mathrm{XY})$. At the age of 2 years the proband had chest X-ray and the MRI of vertebral column which disclosed the presence of butterfly vertebra of Th2 and Th4. Upon repeated ECHO examination the PFO tended to be less and less haemodynamically significant (at the age of 2 years only trace PFO was noted). Endocrinological assays done between 2nd and 4th years of age showed normal levels of growth hormone, but at 4 years of age subclinical hypothyroidism was diagnosed. Holter exam performed at age 5 years and 4 months was unremarkable. The boy was re-investigated in the genetic clinic at the age of 8 years and 4 months. Dysmorphic features seen during his first evaluation were still conspicuous. His body measurements were as follows: height $120.8 \mathrm{~cm}$ (below 3rd percentile), body weight $23.6 \mathrm{~kg}$ (10th-25th percentile). Bone age assessment based on left carpal X-ray was relevant to the metrical age, and the IGF-1 levels were unremarkable. The patient still presented with hypothyroidism and required a daily substitution of $25 \mu \mathrm{g}$ L-thyroxine. Ophthalmologic exam except for right-sided choroidal and retinal coloboma revealed convergent strabismus and hypermetropic astigmatism of the right eye $\left(+1.5 \mathrm{Dsph} /-0.5\right.$ Dcyl ax $\left.150^{\circ}=1.0\right)$, whereas visual acuity of the left eye was 1.0. Psychomotor development was apparently normal. Family history was non-contributory.

\section{Methods}

Cytogenetic and Fluorescent In Situ Hybridization (FISH) studies

Chromosomal analysis on the basis of GTG technique at 550 band resolution per haploid genome was performed on peripheral blood lymphocytes of the patient and his parents. FISH was carried out with use of $5 \mathrm{p} / 5 \mathrm{q}$ subtelomeric probes (TelVysion probe 5p/5q, Vysis) according to the manufacturer's protocols.

\section{Sequencing and MLPA}

Genomic DNA was extracted from peripheral blood leukocytes according to salting-out method. The local ethics committee (Institutional Review Board at Poznan University of Medical Sciences) approved the study and written, informed consent was obtained from all participants or their legal guardians prior to genetic testing. The entire coding sequences of the TBX5 (GenBank NM_000192) and SALL4 (GenBank NM_020436) genes comprised of eight and four exons respectively, and the flanking intronic regions were amplified in PCR reactions and directly sequenced using dye-terminator chemistry (kit v.3, ABI 3130XL). Sequences of the primers used for amplification and sequencing PCR reactions are given in Tables 1 and 2. PCR conditions used for amplification of both genes were as follows: 40 cycles, denaturation in $95^{\circ} \mathrm{C}$ $\left(30^{\prime}\right)$, annealing $\left(30^{\prime}\right)$ with temperature starting from $63^{\circ} \mathrm{C}$, decreasing to $55^{\circ} \mathrm{C}$ (touchdown PCR $-0.2^{\circ} \mathrm{C}$ per cycle), and elongation in $72^{\circ} \mathrm{C}\left(45^{\prime}\right)$. Multiplex ligation-dependent probe amplification (MLPA) for all exons of both TBX5

Table 1 Sequences of the primers used for TBX5 gene (MIM ID*601620; GenBank NM_000192) amplification and sequencing

\begin{tabular}{|c|c|c|c|}
\hline Exon name (fragment) & Forward primer sequence $5^{\prime}-3^{\prime}$ & Reverse primer sequence $5^{\prime}-3^{\prime}$ & Product size (bp) \\
\hline TBX5_e2 & TCTCTCTCTGTCСTCCCCAC & CAAGAGAAGCCGAGCAGG & 310 \\
\hline TBX5_e3 & GGGAAGGAATGCCCACTAC & TTCCaagccaccttttcttc & 231 \\
\hline TBX5_e4 & TTAAAATGGATGGAGGCTGC & TITTGGGAGAAGGTTCCAC & 256 \\
\hline TBX5_e5 & GTGCAGTGCGCTACCTCC & GAAACCCagtgagaagaaggg & 279 \\
\hline TBX5_e6 & GGTITATCTGGAGACAAAGGG & CAGGAAAACCTTGCAGATTC & 293 \\
\hline TBX5_e7 & CATGTCCTGAGGTGGTCTTG & GTTGCTGCTGGCTTACCTG & 232 \\
\hline TBX5_e8 & TCAGCCACTCAGGAAATCTG & CCCCAACCCAAGGAAAGG & 356 \\
\hline TBX5_e9 & CTCCACTITTAGCTGCCTGG & TAGATCAGCATCCAGCGACC & 797 \\
\hline
\end{tabular}




\begin{tabular}{|c|c|c|c|}
\hline Exon name (fragment) & Forward primer sequence $5^{\prime}-3^{\prime}$ & Reverse primer sequence $5^{\prime}-3^{\prime}$ & Product size (bp) \\
\hline SALL4_e1 & GGGGTAAATTTCCCAACTCC & GCGTACGTCCGGGAAGC & 263 \\
\hline SALL4_e2(a) & atagatgtgagcgacggtgc & AAGGTCTTCAGAGTGTCGGC & 729 \\
\hline SALL4_e2(b) & TGGTGCCAACAGCATCC & CACTITGTCCTGGAACTCGG & 730 \\
\hline SALL4_e2(c) & CTGTCTGTGGTCATCGCTTC & GCATCACGGCATTAGTGAAC & 684 \\
\hline SALL4_e2(d) & AGACACACCTTGGGGTTCAC & TAAAGTTCAACCCAGGCTCC & 708 \\
\hline SALL4_e3 & AAAGATCTCTTITGCTTTGAAGAG & TGCCAATAAGAAGACACCTGG & 420 \\
\hline SALL4_e4 & ATTCTTGGCTTGCCAGTGAG & TCGTGATTGTAGCACTTGCC & 652 \\
\hline
\end{tabular}

and SALL4 genes was performed by means of P180-B1 commercial kit according to the manufacturer's protocol (MRC Holland).

\section{Array comparative genomic hybridization (array CGH)}

Array comparative genomic hybridization (array $\mathrm{CGH}$ ) was carried out with the use of two independent microarrays: whole-genome $180 \mathrm{~K}$ oligonucleotide array (Agilent) and $135 \mathrm{k}$ NimbleGen oligonucleotide CGX array (Roche NimbleGen) according to standard protocols provided by the manufacturers. In the first case, analysis was performed with Feature Extraction and CGH Analytics software (Agilent), with the following settings used: Aberration Algorithm: ADM-2; Threshold: 6.0; Window Size: 0.2 Mb; Filter: 5 probes, $\max \log 2$ ratio $=0.29$. In the second case, analysis was done with NimbleScan (Roche NimbleGen) and Genoglypix ${ }^{\circledR}$ software (Signature Genomics).

\section{Quantitative real-time PCR (qPCR)}

To independently test for a number of 5q35.2-5q35.3 copies we developed a qPCR assay. We used a set of five primer pairs, three of which were located within the duplicated region and two lying centromeric against the duplication start point. qPCR was performed in a total volume of $12 \mu \mathrm{l}$ in each well containing $6 \mu \mathrm{l}$ of SYBR Green PCR Master Mix (Applied Biosystems), $5 \mu \mathrm{l}$ of genomic DNA $(1 \mathrm{ng} / \mathrm{ml})$, and $1 \mu \mathrm{l}$ of primers $(0.2 \mathrm{mmol}$ each $)$. All samples were run in triplicate in separate wells to allow for the quantification of the target sequences normalized to Albumin $(A L B)$. PCR conditions were as follows: initial denaturation step at $95^{\circ} \mathrm{C}$ followed by 40 cycles (denaturation at $95^{\circ} \mathrm{C}$ for $15 \mathrm{~s}$, annealing with elongation at $60^{\circ} \mathrm{C}$ for $1 \mathrm{~min}$ ). By use of calibrator DNA derived of a normal healthy control, the gene copy number was measured on the basis of the comparative DDCt method. In addition, we performed a sex determination for the individuals, calculating the Factor VIII (F8) exon 3 relative to our endogenous control Albumin, to assure its reliability. Primer sequences for $A L B$ and $F 8$ were as follows: $A L B \_F$ tgttgcatgagaaaacgcca, $A L B \_R$ - gtcgcctgttcaccaaggat; $F 8 \_F$ gccaagaagcatcctaaaacttg, $F 8 \_R$ - ggcgaggactaagggagcat.

\section{Additional probands with bilateral radial aplasia}

To identify further probands and test the frequency of $5 q 35$ duplication we screened a cohort of another 8 unrelated sporadic patients (6 males and 2 females) with bilateral radial agenesis and absent thumbs. All patients were of Polish ethnicity and were seen in our genetic clinic at different ages varying from 3 months to 31 years. Four cases manifested isolated limb malformation, whereas the other four presented with additional features comprising congenital heart defect (3 cases), and mental retardation (1 case). The patients were prescreened by bi-directional sequencing and MLPA for TBX5 and SALL4 mutations and turned out to be negative. Additionally, a patient affected by mental retardation was analyzed by means of GTG banding, which showed normal result.

\section{Case presentation}

Chromosomal analysis done on peripheral blood lymphocytes (conventional GTG banding at 550 band resolution) was unremarkable in the proband as well as in both parents. Differential diagnosis in the proband included Holt-Oram and Okihiro syndromes, therefore molecular screening of TBX5 and SALL4 genes was performed by means of sequencing and MLPA. The study ruled out the presence of point mutations and intragenic copy number changes within the coding portion of both genes. Array CGH of proband's DNA detected a duplication on 5q35.2-5q35.3 between positions 175243241180645010 (Agilent platform) and 175234642-180619169 (Roche NimbleGen platform) according to HG18 (for schematic view of Roche aCGH results see Figure 2A). Next, qPCR with a set of primers highly specific for 5q35.2-5q35.3 showed three copies of the region of interest in the proband, hence confirming array CGH results. Two copies of the investigated region were found in both parents (Figure 2D; for primer sequences and coordinates see Table 3). The same qPCR assay was used to study a cohort of 8 non-consanguineous probands with radial agenesis (with or without heart defect) negative for $T B X 5$ and SALL4 mutations. qPCR test revealed no copy number change in any of the probands. 


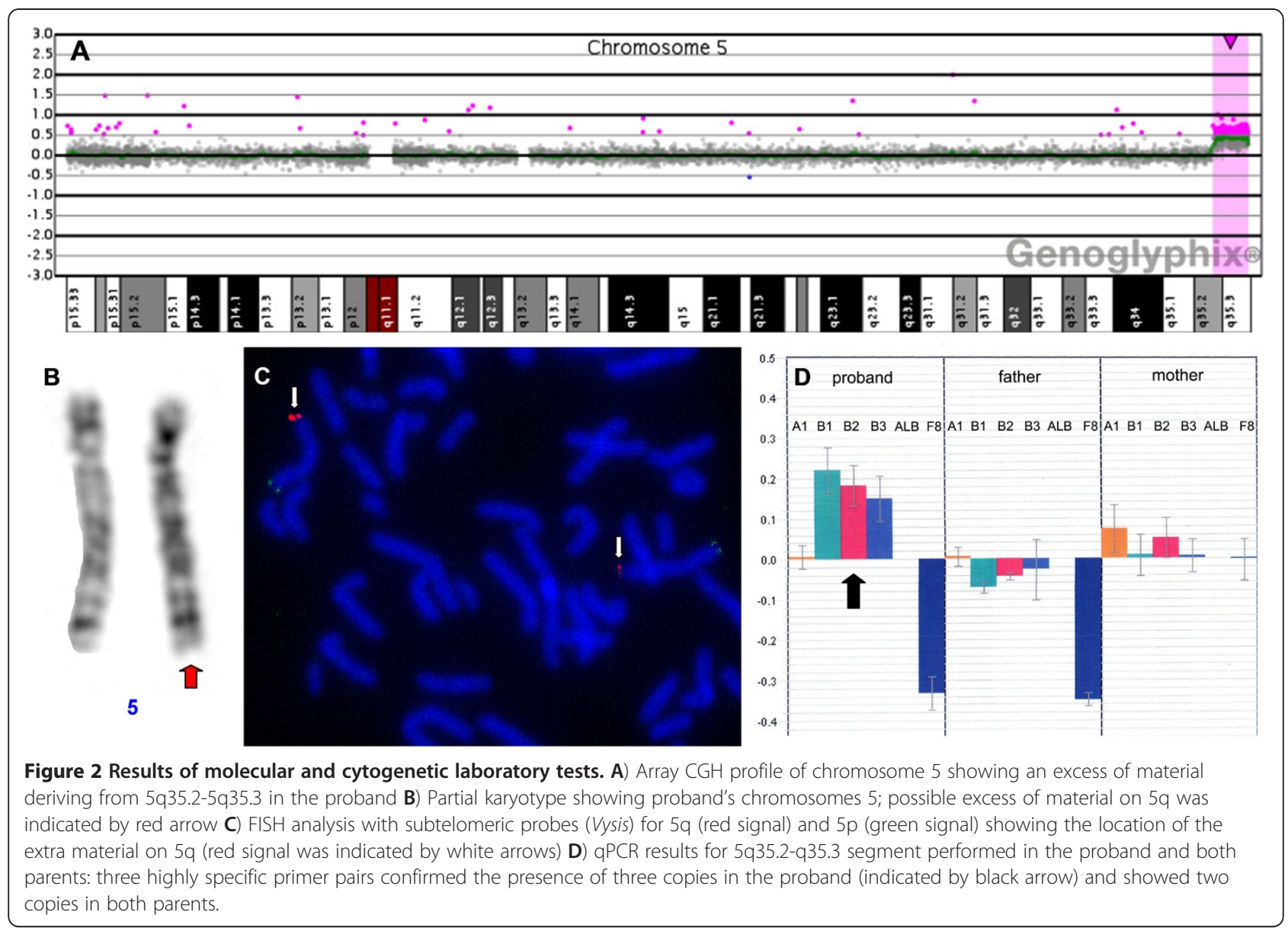

Retrospective analysis of GTG-banded chromosomes identified possible gain on 5q (Figure 2B), which could be easily missed without array CGH results. FISH with $5 \mathrm{p} / 5 \mathrm{q}$ subtelomeric probes was used on metaphase and interphase chromosomes to localize the extra copy of distal $5 \mathrm{q}$. The signals from $5 \mathrm{q}$ FISH probe were detected on chromosome 5 in the proband as well as in both parents, thus confirming that the duplication did not result from parental chromosomal translocation (Figure 2C).

Table 3 Sequences of the primers used for quantifying the number of copies of $5 q 35.2-5 q 35.3$, along with coordinates for each amplified genomic region (HG18), its relative position with regard to the start point of the duplication, and the number of copies detected in the proband

\begin{tabular}{|c|c|c|c|c|c|}
\hline Primer name & Primer sequence & $\begin{array}{l}\text { Chromosomal } \\
\text { band }\end{array}$ & $\begin{array}{l}\text { Coordinates of the } \\
\text { amplicon (HG18) }\end{array}$ & $\begin{array}{l}\text { No of copies detected } \\
\text { in the proband }\end{array}$ & $\begin{array}{l}\text { Position of the amplicon in ref. } \\
\text { to the start of the duplication }\end{array}$ \\
\hline 5q35.2_A1_F & AACAGGCTCACGCCTTCTTA & $5 q 35.2$ & $175182611-175182696$ & 2 & $-61 k b$ \\
\hline 5q35.2_A1_R & GAAGCACCCAACACATCCTT & & & & \\
\hline 5q35.2_A2_F & CCTTACCAGCAGGGACACAT & $5 q 35.2$ & $175201237-175201316$ & 2 & $-42 k b$ \\
\hline $5 q 35.2 \_A 2 \_R$ & CATGGCCCTCCTACACATCT & & & & \\
\hline 5q35.3_B1_F & GTGGAATGATCACGATGCTG & $5 q 35.3$ & $175286270-175286357$ & 3 & $+43 \mathrm{~kb}$ \\
\hline 5q35.3_B1_R & TGCACAGTCCAACAGACACA & & & & \\
\hline 5q35.3_B2_F & CTGCTCAGCGGGATCTATGT & $5 q 35.3$ & $176356609-176356696$ & 3 & $+1,12 \mathrm{Mb}$ \\
\hline 5q35.3_B2_R & TCAAGTCTGCCCCAACTCTT & & & & \\
\hline 5q35.3_B3_F & CCAATCCTGGCATGAGACTT & $5 q 35.3$ & $179355063-179355146$ & 3 & $+4,12 \mathrm{Mb}$ \\
\hline 5q35.3_B3_R & GCAAACTGTGTGGGAATCCT & & & & \\
\hline
\end{tabular}


According to Map Viewer browser the duplicated region contains 154 genes, including 52 OMIM genes, out of which 13 are known to be disease causing (see Figure 3). The most proximal disease associated gene lying outside the duplication (around 1.1 Mb centromeric from the duplicated segment) is a homeobox containing gene MSX2 also known as $H O X 8$.

\section{Discussion}

Our patient carries the smallest pure distal duplication of chromosome $5 q$ (i.e. terminal part of $5 q 35.2$ band and the entire $5 \mathrm{q} 35.3$ band). The phenotype of our patient showed significant overlap with Hunter-McAlpine syndrome, with such common features as short stature, heart defect, cryptorchidism, and craniofacial dysmorphism including prominent widened nasal bridge, almond-shaped eyes, thin vermillion of upper lip, and low-set dysplastic ears. In addition, our patient manifested less frequent symptoms (i.e. hypothyroidism) or even unique findings such as bilateral radial agenesis with absent thumbs, bilateral ulnar hypoplasia, abnormal biliary vesicle, and unilateral choroidal and retinal coloboma. Interestingly, absent thumbs were reported so far only in a single patient with an atypical copy number variation (CNV) on $5 q$, which was the interstitial triplication of the distal $5 \mathrm{q}$ segment encompassing MSX2 (6.56 Mb, coordinates according to HG18: 173897858-180456069). Since absent thumbs were never noted in cases with a distal $5 \mathrm{q}$ duplication, the authors hypothesized that the relatively severe limb malformation was due to the increased dosage of $5 q$ copies [9]. Although caused solely by a pure duplication, the skeletal phenotype in our patient was more severe and involved bilateral radial aplasia with completely absent Ist digital rays (thumbs and Ist metacarpals), and ulnar hypoplasia with bowing. The defect seen in our patient as well as in the former case can be both categorized to radial ray deficiency spectrum. We therefore suggest that limb malformation presented by our index was a more severe manifestation of a common defect, namely radial ray deficiency. Of note, the chromosomal microduplication identified in our proband (terminal 5.4-5.6 Mb) did not encompass the MSX2 gene, which is located $1.1 \mathrm{Mb}$ centromeric relative to its beginning. The MSX family, comprises MSX1 and MSX2 homeobox containing genes, which are important developmental regulators involved in the processes of limb, craniofacial, and ectoderm formation in vertebrates [10]. For example, MSX1 is essential for tooth and facial bone development and its mutations lead to Witkop syndrome also known as nail dysplasia with hypodontia [11]. Moreover, duplications of MSX2 cause Boston type craniosynostosis [6,12], whereas intragenic alterations or gene deletions result in parietal foramina, a disorder of deficient ossification of the skull $[13,14]$. It has been therefore postulated that duplications of $M S X 2$ are responsible for craniosynostosis and brachydactyly in Hunter-McAlpine patients. Thus far, $5 \mathrm{q}$ distal trisomy has never been associated with the absence of digits. However, based on the observation of a $5 q$ tetrasomy carrying patient, it has been hypothesized that multiple copies of $5 \mathrm{q}$ (including MSX2) result in a more severe skeletal anomaly such as absent thumbs. Clinical manifestation of our proband and the underlying genetic defect show that in the case of $5 q$ gain, an extra copy (copies) of MSX2 is not necessary to give rise to a severe limb phenotype involving not only absent thumbs, but also bilateral radial aplasia and hypoplastic ulnae. Importantly, the size of the duplication in our case was smaller than that reported for other trisomy $5 \mathrm{q}$ patients and mapped 1.1 Mb telomeric to the MSX2. A plausible candidate gene causative for the limb malformation in our proband could be FGFR4. This gene is duplicated in our patient and maps around 1.3 Mb from the beginning of CNV. FGFR4 encodes for a protein, which is a type 4 receptor for fibroblast growth factors (FGFs). Members of FGF protein family are involved in FGF signalling pathway and play an important role during limb development. FGF4 along with FGF8 is secreted by apical ectodermal ridge (AER) which maintains the FGF10 signal and induces proliferation in the mesoderm $[15,16]$. For

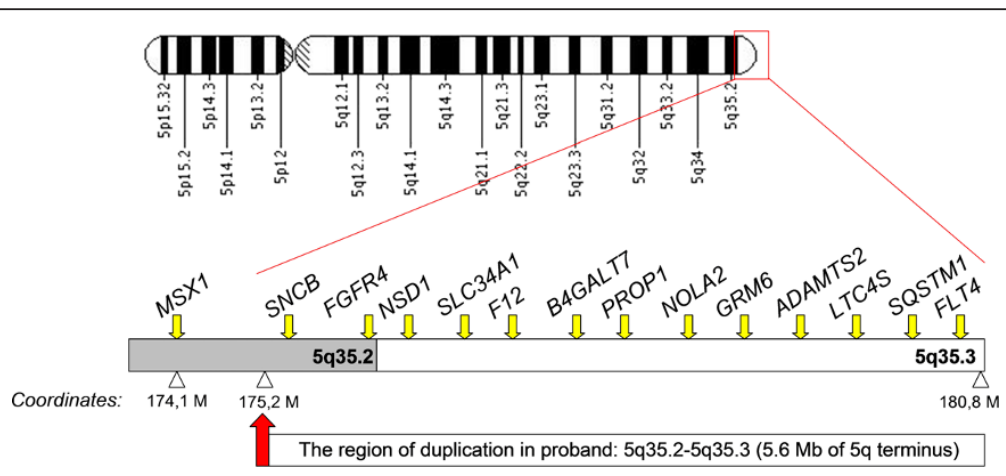

Figure 3 An ideogram of the chromosome 5 with schematic representation of the duplication identified in our proband. All 13 diseaseassociated genes are listed above the sketch representing $5 \mathrm{q}$ terminus. 
example, loss of both Fgf4 and Fgf8 in mice is thought to result in a reduction of the proliferation rate in distal mesenchyme, followed by downregulation of Fgflo and premature degeneration of AER. Hence, in the absence of both Fgf4 and Fgf8, increased mesenchymal cell death results in a reduction in limb bud size [17]. So far there has been no report on radial agenesis and absent thumbs in other patients carrying $5 \mathrm{q}$ duplication encompassing FGFR4, suggesting that an extra copy of this gene is not sufficient to give rise to the limb phenotype. Noteworthy, FGFR4 maps about $1.3 \mathrm{Mb}$ from the beginning of the duplication detected in our proband, which is relatively the closest position to the chromosomal breakage site for all known 5q duplications. Since both the limb malformation as well as the underlying genetic defect are unique in our patient we propose that a position effect resulting in altered long-range regulation of the FGFR4 (or possibly MSX2) may be the underlying patomechanism for limb malformation in both our and $5 \mathrm{q}$ tetrasomy patient. Alternatively, an extra copy and/or dysregulation of another gene may be responsible for radial agenesis.

The high frequency of congenital heart abnormalities in patients with a $5 \mathrm{q}$ trisomy was attributed to the altered dosage of one or two cardiac developmental genes, NKX2-5 and CSX1, both mapping to chromosome 5q34 $[18,19]$. Interestingly, patient with the smallest pure distal duplication of 5q (encompassing terminal 6.4 of 5q35.2-q35.3) described to date in the literature, did not show any cardiac abnormality. This pointed to an observation that the direct duplication of 5q35.2-q35.3 may not lead to a cardiac phenotype [8]. In contrast, our patient carried even smaller distal duplication of $5 \mathrm{q}$, however presented with a complex congenital heart defect including dextrocardia, dextroversion, and PFO. This may suggest that not only NKX2-5 or CSX1, but also other genes or regulatory elements located in distal $5 q$ play an important role in the process of embryonic heart formation.

A duplication of the distal arm of chromosome $5 \mathrm{q}$ is known to be associated with short stature and microcephaly, and an increased dosage of NSD1 gene was proposed to be responsible for a combination of these two features [8]. Deletions and point mutations of the NSD1 gene cause Sotos syndrome with cerebral gigantism, overgrowth and macrocephaly [20]. It is theoretically possible, as suggested by Chen et al. [8], that dosage changes (decrease or increase) of NSD1 lead to opposite phenotypes. Nonetheless, our patient had a duplication encompassing NSD1 but although short statured, he did not presented with a microcephaly. This may be explained by the incomplete penetrance of the candidate microcephaly gene.

\section{Conclusions}

In conclusion, we postulate that a terminal distal trisomy of $5 \mathrm{q} 35.2-5 \mathrm{q} 35.3$, which maps $1.1 \mathrm{Mb}$ telomeric to the
MSX2 gene is causative for both radial agenesis and complex heart defect in our proband. Although duplications of $M S X 2$, a highly conserved developmental gene which plays a major role in cardiac and bone morphogenesis were considered responsible for at least some skeletal symptoms (including limb malformations) in $5 \mathrm{q}$ trisomy patients, we provide evidence that even more distally located duplications may give rise to a more severe limb phenotype. Based on this observation, we propose that other genes or altered FGFR4 (or possibly MSX2) long range regulation contribute to the development of radial agenesis and absent thumbs.

Finally, we studied a small cohort of 8 unrelated probands manifesting bilateral radial agenesis with or without heart defect, who were negative for TBX5 and SALL4 mutations. None of them had $5 \mathrm{q}$ duplication detected upon qPCR, suggesting that this kind of molecular defect is not a common cause of radial agenesis and associated limb phenotype.

\section{Consent}

Written informed consent was obtained from the patient's parents to take part in the study as well as for publication of the images (including full-face pictures). A copy of the written consent is available for review by the Editor-inChief of this journal. Informed consent was obtained from 8 unrelated probands or their legal guardians to participate, and include details in the manuscript.

\section{Abbreviations \\ AER: Apical ectodermal ridge; ASD: Atrial septal defect; CGH: Comparative genomic hybridization; CNV: Copy number variation; LVNC: Left ventricular noncompaction; PFO: Persistent foramen ovale; qPCR: Quantitative polymerase chain reaction; VSD: Ventricular septal defect.}

\section{Competing interests}

The authors declare no competing interests.

\section{Authors' contributions}

AJ, consulted the family, conceived the manuscript, performed molecular testing; AS, performed molecular testing of the patients and parents; DS, performed GTG banding and FISH studies; TT, consulted the family of interest; MJB, critically revised the manuscript; $A L B$, critically revised the manuscript. All authors read and approved the final manuscript.

\section{Acknowledgements}

We are grateful to the patient, his parents, and the referring physicians for participating in this study. This work was supported by a grant from the Polish Ministry of Science and Higher Education (495/N-NIEMCY/2009/0) and a grant from National Science Centre (UMO-2011-03-D-NZ2-06136).

\section{Author details}

${ }^{1}$ Department of Medical Genetics, University of Medical Sciences in Poznan, 55 Grunwaldzka Street, pav. 15, Poznan 60-352, Poland. ${ }^{2}$ NZOZ Center for Medical Genetics GENESIS, Poznan, 4 Grudzieniec Street, Poznan 60-601, Poland. ${ }^{3}$ National Institute of Public Health - National Institute of Hygiene, Department of Environmental Hygiene, 24 Chocimska Street, Warsaw 00-791, Poland. ${ }^{4}$ Department of Orthopedics and Traumatology, University of Medical Sciences, Poznan, 135/147 28 czerwca 1956 r. Street, Poznan 61-545, Poland. 
Received: 22 May 2012 Accepted: 18 January 2013

Published: 24 January 2013

\section{References}

1. Hunter AG, Dupont B, McLaughlin M, Hinton L, Baker E, Ades L, Haan E, Schwartz CE: The Hunter-McAlpine syndrome results from duplication 5q35-qter. Clin Genet 2005, 67:53-60.

2. Curry CJR, Loughman WD, Francke U, Hall BD, Golbus MS, Derstine J, Epstein CJ: Partial trisomy for the distal longarm of chromosome 5 region q34-qter: A new clinical recognizable syndrome. Clin Genet 1979, 15:454-461.

3. Rodewald A, Zankl M, Gley EO, Zang KD: Partial trisomy 5q: Three different phenotypes depending on different duplication segments. Hum Genet 1980, 55:191-198.

4. Jones LA, Jordan DK, Taysi K, Strauss AW, Toth JK: Partial duplication of the long arm of chromosome 5: A case due to balanced paternal translocation and review of the literature. Hum Genet 1979, 51:37-42.

5. Abuelo DN, Ahsanuddin AN, Mark HFL: Distal $5 q$ trisomy resulting from an X;5 translocation detected by chromosome painting. Am J Med Genet 2000, 94:392-399.

6. Wang JC, Steinraths M, Dang L, Lomax B, Eydoux P, Stockley T, Yong SL, Van Allen Ml: Craniosynostosis associated with distal 5q-trisomy: Further evidence that extra copy of MSX2 gene leads to craniosynostosis. Am J Med Genet Part A 2007, 143A:2931-2936.

7. Kariminejad A, Kariminejad R, Tzschach A, Ullmann R, Ahmed A, AsghariRoodsari A, Salehpour S, Afroozan F, Ropers HH, Kariminejad MH: Craniosynostosis in apatient with 2q37.3 deletion $5 q 34$ duplication: Association of extra copy of MSX2 with craniosynostosis. AmJ Med Genet Part A 2009, 149A:1544-1549.

8. Chen C-P, Lin S-P, Lin C-C, Chen Y-J, Chern S-R, Li Y-C, Hsieh L-J, Lee C-C, Pan C-W, Wang W: Molecular cytogenetic analysis of de novo dup(5) (q35.2q35.3) and review of the literature of pure partial trisomy $5 q$. Am J Med Genet Part A 2006, 140A:1594-1600.

9. Sellars EA, Zimmerman SL, Smolarek T, Hopkin RJ: Ventricular noncompaction and absent thumbs in a newborn with tetrasomy 5q35.2-5q35.3: An association with Hunter-McAlpine syndrome? Am J Med Genet Part A 2011, 155:1409-1413.

10. Alappat S, Zhang ZY, Chen YP: Msx homeobox gene family and craniofacial development. Cell Res 2003, 13:429-442.

11. Jumlongras D, Bei M, Stimson JM, Wang WF, DePalma SR, Seidman CE, Felbor U, Maas R, Seidman JG, Olsen BR: A nonsense mutation in MSX1 causes Witkop syndrome. Am J Med Genet 2001, 69:67-74.

12. Bernardini L, Castori M, Capalbo A, Mokini V, Mingarelli R, Simi P, Bertuccelli A, Novelli A, Dallapiccola B: Syndromic craniosynostosis due to complex chromosome 5 rearrangement and MSX2 gene triplication. Am J Med Genet Part A 2007, 143A:2937-2943.

13. Wilkie AO, Tang Z, Elanko N, Walsh S, Twigg SR, Hurst JA, Wall SA, Chrzanowska KH, Maxson RE Jr: Functional haploinsufficiency of the human homeobox gene MSX2 causes defects in skull ossification. Nat Genet 2000, 24:387-390.

14. Wuyts W, Reardon W, Preis S, Homfray T, Rasore-Quartino A, Christians H, Willems PJ, VanHul W: Identification of mutations in the MSX2 homeobox gene in families affected with foramina parietalia permagna. Hum Mol Genet 2000, 9:1251-1255.

15. Crossley PH, Minowada G, MacArthur CA, Martin GR: Roles for FGF8 in the induction, initiation, and maintenance of chick limb development. Cell 1996, 84:127-136.

16. Vogel A, Rodriguez C, Izpisua-Belmonte JC: Involvement of FGF-8 in initiation, outgrowth and patterning of the vertebrate limb. Development 1996, 122:1737-1750.

17. Yu K, Ornitz DM: FGF signaling regulates mesenchymal differentiation and skeletal patterning along the limb bud proximodistal axis. Development 2008, 135:483-491.

18. Shiojima I, Komuro I, Inazawa J, Nakahori Y, Matsushita I, Abe T, Nagai R: Yazaki: Assignment of cardiac homeobox gene CSX to human chromosome 5q34. Genomics 1995, 27:204-206.
19. Schott J-J, Benson DW, Basson CT, Pease W, Silberbach GM, Moak JP, Maron BJ, Seidman CE, Seidman JG: Congenital heart disease caused by mutations in the transcription factor NKX2-5. Science 1998, 281:108-111.

20. Kurotaki N, Imaizumi K, Harada N, Masuno M, Kondoh T, Nagai T, Ohashi H, Naritomi K, Tsukahara M, Makita Y, Sugimoto T, Sonoda T, Hasegawa T, Chinen Y, Tomita H, Kinoshita A, Mizuguchi T, Yoshiura K, Ohta T, Kishino T, Fukushima Y, Niikawa N, Matsumoto N: Haploinsufficiency of NSD1 causes Sotos syndrome. Nat Genet 2002, 30:365-366.

doi:10.1186/1471-2350-14-13

Cite this article as: Jamsheer et al.: Bilateral radial agenesis with absent thumbs, complex heart defect, short stature, and facial dysmorphism in a patient with pure distal microduplication of 5q35.2-5q35.3. BMC Medical Genetics 2013 14:13.

\section{Submit your next manuscript to BioMed Central and take full advantage of:}

- Convenient online submission

- Thorough peer review

- No space constraints or color figure charges

- Immediate publication on acceptance

- Inclusion in PubMed, CAS, Scopus and Google Scholar

- Research which is freely available for redistribution

Submit your manuscript at www.biomedcentral.com/submit
C BioMed Central 